\title{
A Decision Support Methodology for Remediation Planning of Concrete Bridges
}

\author{
Maria Rashidi ${ }^{1}$ and Brett Lemass ${ }^{2}$
}

\begin{abstract}
Bridges are critical and valuable components in any road and rail transportation network. Therefore bridge remediation has always been a top priority for asset managers and engineers, but identifying the nature of true defect deterioration and associated remediation treatments remains a complex task. Nowadays Decision Support Systems (DSS) are widely used to assist decision makers across an extensive spectrum of unstructured decision environments. The main objective of this research is to develop a requirements-driven methodology for bridge monitoring and maintenance which has the ability to assess the bridge condition and find the best remediation treatments using Simple Multi Attribute Rating Technique (SMART); with the aim of maintaining a bridge within acceptable limits of safety, serviceability and sustainability.
\end{abstract}

Keywords: Decision Support System (DSS), condition assessment, risk assessment, remediation, MAUT, SMART

\section{INTRODUCTION}

The deterioration of structural assets is a common problem throughout the world. More specifically, deficiencies related to ageing bridges have become a major concern for engineers, asset managers and society globally. The collapse of the bridge carrying Highway $35 \mathrm{~W}$ over the Mississippi River in Minneapolis, USA, is an event that sparked world interest in infrastructure. The bridge had been known to be structurally deficient since the 1990s, when corrosion in a number of beam members and connection plates was identified. Although known, these faults had not been prioritised to allow sufficient remediation to take place, and so the bridge was left to deteriorate. A debate on how safe the country's ageing infrastructure is, and what funding is required to fix that infrastructure, has been occurring in the USA.

This debate is not confined to the United States, with the operation, maintenance, repair and eventual renewal of our "built environment" representing a major, rapidly growing cost [1]. In 2003 the structural condition of the Menangle rail bridge, the oldest iron bridge in New South Wales (NSW), was cause for concern with the bridge being closed for a month while it was assessed. These concerns along with the lack of importance given to its condition later led to an investigation by the NSW Independent Commission Against Corruption (ICAC). Major public infrastructure attracts widespread media attention due to the potential risk to the public if there is a breakdown in that infrastructure. While government and media attention is focused on large public infrastructure issues, seemingly innocuous local bridges also need to be effectively maintained.

Bridges are often subjected to high loads, harsh environments, and accidental damage. Determining what level of repair is required to achieve the most economical lifespan from a bridge structure has been a source of dilemma for asset managers and owners for many years. It is possible to determine what constraints are relevant in ageing bridge structures, how to use these constraints to appropriately rate the condition of structures, and to determine an economical but timely plan of remediation to extend their working life.

Decision support processes have been widely used to assist managers to determine the most appropriate paths to take $[1,2,3,4,5,6]$. Whether remediation constraints are technical, economic, environmental or social, applying decision support principles will assist asset owners and managers in clarifying in a transparent manner what may be the best course of remediation for a given bridge.

There are approximately 33,000 bridges in Australia. Over $50 \%$ of these bridges are considered to be in a fair or poor state (40\% fair and $15 \%$ in poor condition) $[7,8]$. Due to the substantial role of bridges in road networks, any failure or deficiency of a bridge may have severe consequences for the safety of individuals and property. It may also restrict or interrupt the traffic flow over a large part of the network.

In accordance with the limited funding for bridge management, remediation strategies have to be prioritised.

\footnotetext{
${ }^{1} \mathrm{PhD}$ Candidate, University of Wollongong, Northfield Ave, Wollongong, 2522, NSW, Australia, mpr223@uow.edu.au (*Corresponding Author)

${ }^{2}$ Associate Professor, University of Wollongong, Northfield Ave, Wollongong, 2522, NSW, Australia, blemass@uow.edu.au
} 
A conservative bridge assessment will result in unnecessary actions, such as costly bridge strengthening or repairs [9]. On the other hand, any bridge maintenance negligence and delayed actions (or ignoring the cause of defects) may lead to heavy future costs or degraded assets [8].

The service life of a bridge can be subdivided into four different phases:

Phase A-Design and construction

Phase B-Propagation of deterioration has not yet begun but initiation processes are underway

Phase C-Damage propagation has just started

Phase D- Extensive deterioration is occurring

In line with the Law of Fives [10], one dollar spent in Phase A equals five dollars spent in Phase B; twenty-five dollars in Phase $\mathrm{C}$ equals hundred and twenty five dollars in Phase D.

Bridge design codes and specifications should be able to ensure good engineering quality in Phase A.

Bridge monitoring and maintenance must be accomplished during Phase B to prevent the structure from progressing into Phase $\mathrm{C}$ and $\mathrm{D}$.

A pivotal responsibility for asset managers in charge of bridge remediation is to make transparent decisions which result in the lowest predicted losses in recognised constraint areas [11].

Decision-making in this field is more complicated than it was in the past due to two governing reasons. Firstly, expanding technology and communication systems have spawned a greater number of feasible solution alternatives from which a decision-maker must choose. Secondly, the increased level of structural complexity and design competition typical of today's problems can result in a chain reaction magnification of costs if an error should occur. Deficiencies related to aging bridges have become a major concern for asset managers and society globally and particularly in Australia.

The increasing level of decision support system implementation in organisations over the past two decades is strong proof that DSS are feasible and well accepted managerial tools [12, 13]. These developed systems are now providing enormous benefits, both in time and cost savings [14].

A conventional decision support system is broadly defined as an interactive computer-based system that uses a model to identify relevant data in order to make decisions. The word system implies that a DSS is a set of interrelated components [12].

By partially cloning human expert knowledge and suppo rting it with deep algorithmic knowledge, it seems likely th at successful intelligent decision support systems (IDSS) c ould improve user understanding and work productivity, re duce uncertainty and anxiety, and preserve the valuable $\mathrm{kn}$ owledge of experts in short supply. They could also effecti vely save time and investment capital by making domain $\mathrm{k}$ nowledge readily available throughout the decision process.

The research project presented in this paper deals with the development of a knowledge-based decision support model for bridge remediation. The working model includes a procedure for condition assessment in order to prioritise bridges in a network for maintenance fund allocation. The next step is classifying all the viable courses of action, and finally finding the best remediation strategy using Multi Attribute Utility Theory (MAUT).

\section{THE BRIDGE REMEDIATION FRAMEWORK}

The working framework for bridge remediation comprises the process which provides the system inputs (Condition Index, maintenance alternatives and decision constraints), the inference engine (Decision Analysis Tool) and the system output (Remediation Plan).

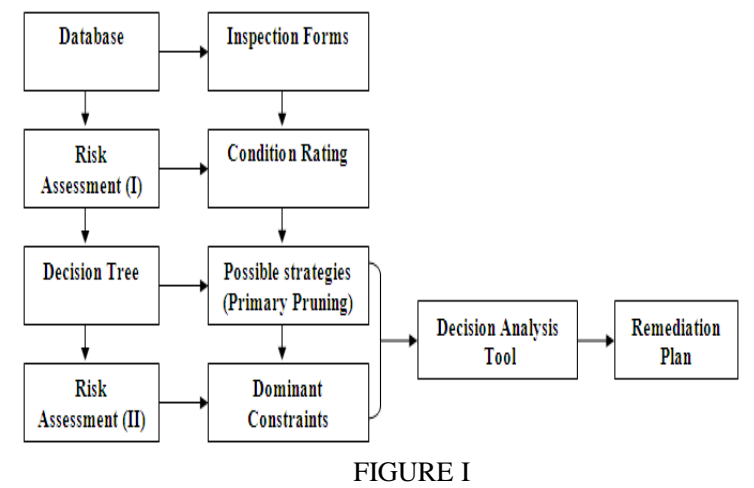

THE BRIDGe REMEDIATION FramEWORK

\section{A. The Database/ Inspection Forms}

Due to increasing numbers of bridges in poor condition and higher traffic limits being carried on roads, many databases and inspection policies have been developed [8]. The effectiveness of a bridge monitoring system is related to its data storage and inspection information. The database stores three types of information: static, semistatic, or upgradeable. Static information includes items such as administrative data, inspection manuals, structural reliability and graphic information. Semi-static information covers cost files, annual budgets, load-bearing capacity and reference state forms. The upgradable information addresses inspection forms which are based on a number of visits to a bridge at specific intervals, balanced by visits under certain circumstances. Inspections performed at fixed intervals are called periodic inspections, while special ones are referred to as non-periodic inspections [15]. Current bridge inspection methodologies have limitations and are generally empirical mostly based on filed experience and engineering assessments.

\section{B. Risk Assessment (I): Condition Rating}

Bridge condition assessment based on field inspections is a fundamental step for providing the appropriate inputs for any condition rating system. The reliability of decisions to find a remediation strategy or fund allocation is highly dependent upon the thoroughness of the condition assessment and diagnosis process. Many bridge agencies commonly use only structural condition. Parameters such as functionality and criticality may not be specifically addressed in existing practices. The developing condition rating method described herein is an important step in 
adding more holism and objectivity to the current approaches. The main factors which should be addressed are described in the following sections. To quantify the parameters, numbers from 1 to 4 have been included which demonstrate the potential level of severity [18].

1) Structural Deficiency Factor (SDF): This refers to the rate of deterioration or decay of constituent bridge material (e.g. cracking, corrosion and delamination, failure of joints and bearing).

With the purpose of being consistent with the current bridge inspection practices in Australia, the recommended methodology is based on four condition states defined by the Roads and Traffic Authority (RTA) in New South Wales in which the bridge element condition ranges from 1 to 4 in rising order. The general description of the four condition states for reinforced concrete bridge elements is presented in Table I [16].

TABLE I

Condition STATES FOR CONCRETE BRiDge Elements

\begin{tabular}{|l|l|}
\hline $\begin{array}{l}\text { Condition } \\
\text { Rate }\end{array}$ & Description of defects \\
\hline 1 & $\begin{array}{l}\text { The element shows no deterioration. There } \\
\text { may be discolouration, efflorescence and/or } \\
\text { superficial cracking but without effect on } \\
\text { strength and/ or serviceability. }\end{array}$ \\
\hline 2 & $\begin{array}{l}\text { Minor cracks and spalls may be present but } \\
\text { there is no evidence of corrosion of non- } \\
\text { prestressed reinforcement or deterioration } \\
\text { of the prestress system. }\end{array}$ \\
\hline 3 & $\begin{array}{l}\text { Some delaminations and/or spalls may be } \\
\text { present. No evidence of deterioration of the } \\
\text { prestress system. Corrosion of non- } \\
\text { prestressed reinforcement may be present } \\
\text { bot loss of section is minor and does not } \\
\text { significantly affect the strength and/or } \\
\text { serviceability of either the element or the } \\
\text { bridge. }\end{array}$ \\
\hline 4 & $\begin{array}{l}\text { Delaminations, spalls and corrosion of non- } \\
\text { prestressed reinforcement are prevalent. } \\
\text { There may also be exposure and } \\
\text { deterioration of the prestress system } \\
\text { (manifested by loss of bond, broken strands } \\
\text { or wire, failed anchorages, etc). There is } \\
\text { sufficient concern to warrant an analysis to } \\
\text { ascertain the impact on the strength and/or } \\
\text { serviceability of either the element or the } \\
\text { bridge. }\end{array}$ \\
\hline
\end{tabular}

In this system, the bridge is divided into elements generally made of a similar material (most bridges have about ten to twelve elements and bridge sized culverts usually have three to five elements). The inspector estimates and records the quantities of the bridge element in each condition state independently. The total quantity must be measured in the correct units for the elements. The units of measurement are square metres (deck, pier, and pile), metres (joints and railings) or each item (bearing pad, waterway, etc).

The following example shows the bridge element condition concept. The data used in this example has been extracted from a bridge inspection report provided by the RTA for a concrete bridge in the Illawarra region. The condition inspection results of pile elements with a total area of $695 \mathrm{~m}^{2}$ are presented in Table II.

TABLE II

Condition States for Concrete Piles in a Bridge

\begin{tabular}{|l|l|}
\hline Condition Rate & Area $\left(\mathrm{m}^{2}\right)$ \\
\hline 1 & 590 \\
\hline 2 & 3 \\
\hline 3 & 0 \\
\hline 4 & 102 \\
\hline
\end{tabular}

The overall condition of piles $=[(590 \times 1)+(3 \times 2)+(0 \times 3)$ $+(102 \times 4)] /[695 \times 1]=1.44$

As can be seen above the element condition index can be calculated as the current value divided by the initial value of the bridge element. To describe the overall condition status of structural elements, the Element Structural Condition Index (SCI) is introduced as:

$$
E S C I=\frac{\sum(q i \times C i)}{\sum q i} \quad(\text { Equation } 1)
$$

$-q_{i}:$ : quantity of elements reported in condition index $C_{i}$ $-\mathrm{C}_{\mathrm{i}}$ : condition of sub-element $\quad \mathrm{c}_{\mathrm{i}} €(1,2,3,4)$

As can be seen in the ESCI estimation process, deterministic values are used as an approximation for the element value at each of the four condition states. This approximation may not be quite reliable, since data collected through inspection process is usually associated with subjectivity and uncertainty [17].

It should be clearly understood that some elements require more attention than the others in terms of material vulnerability and/or structural significance. For example, a defective main beam will require more urgent attention than the bridge drainage outlets. However the determination of structural/material vulnerability of various bridge elements is a difficult task. Sometimes doing additional structural analysis such as non-destructive testing is unavoidable. Alternatively, bridge experts and inspectors can rely on their own experience and knowledge to determine these factors.

Generally, the prevailing condition (rating) of the particular element may cause some inaccuracies in the overall structural assessment. For example, a minor component with severe deterioration may unreasonably raise the rating value of that element under which the component is grouped. This problem can be dealt with the introduction of element structural significance factor which is not dependent on the prevailing condition of components [19].

The evaluation incorporates many parameters and human judgments that may cause the procedure to be slightly uncertain and imprecise. Efforts have been made to employ a systematic approach to quantify the structural importance of various bridge elements [20, 21, 19, 17]. Tee et al., [20] defined the structural significance as the role of an element in comparison to the other components and quantified this factor for different elements at different 
condition rating based on survey results from 46 inspectors and bridge experts. Dabous and Alkass [17] described the structural importance of a bridge component as the level the component contributes to the overall structural safety and integrity of the bridge and proposed the Analytical Hierarchy Process (AHP) to estimate the value of that parameter. In this research, the element structural significance $(\mathrm{Si})$ and the material vulnerability factor $(\mathrm{m} i)$ have been investigated through conducting semi-structured field interviews with bridge engineers/ inspectors. The outcome of the processed expert judgments considering the results of previous case studies is summarised in TABLE III and TABLE IV respectively.

TABLE III

Structural Significance Factor Si

\begin{tabular}{lc}
\hline Element & $\begin{array}{c}\text { Structural Significance } \\
\text { Factor, } \mathrm{S}_{\mathrm{i}}\end{array}$ \\
\hline $\begin{array}{l}\text { Barrier, Footway, Kerbs, } \\
\text { Joints }\end{array}$ & 1 \\
$\begin{array}{l}\text { Foundation, Abutment, } \\
\text { Wingwall }\end{array}$ & 2 \\
Deck, Bearings & 3 \\
Beams, Headstocks, Piers & 4
\end{tabular}

As can be seen in the tables, both parameters range between 1 and 4 . The higher Si represents the superior structural importance and the greater $\mathrm{M} i$ reflects the higher material vulnerability.

TABLE IV

MAterial Vulnerability Factor M

\begin{tabular}{lc}
\hline Material of the element & $\begin{array}{c}\text { Material Vulnerability } \\
\text { Factor, } \mathrm{M}_{\mathrm{i}}\end{array}$ \\
\hline Steel & 1 \\
Reinforced Concrete & 2 \\
Precast concrete & 3 \\
Pre stressed concrete & 4 \\
Other material & 3 \\
\hline
\end{tabular}

The overall structural importance of concrete bridges can be estimated through the following equation.

$\mathrm{S} . \mathrm{I}=\sum_{i=1}^{n}[(S i \times M i \times E S C I i) / 16 n]$

(Equation 2)

-Si: element structural significance factor

$-\mathrm{M}_{\mathrm{i}:}$ material vulnerability factor

-ESCI $\mathrm{i}_{\mathrm{i}}$ element structural condition index

$-n$ : number of elements

2) Age Factor $(A F)$ : Since bridges are designed to withstand fatigue loading (which increases with time), age is an important parameter involved in structural condition assessment.

The life expectancy of existing bridges is dependent on their age, and major concrete bridges are designed for a service life of 100 years. Durability measures should be adopted for 100 years. When service life is raised further than 50 years, the study of major bridges requires that safety be reconsidered to incorporate coherence into the design [9]. The service life of a bridge will be ended when one of the key components fails to function as designed.

Generally, bridges in the last quarter of their design life (typically 100 years) require more serious remedial actions than in previous quarters.

3) Serviceability Potential Factor (SPF): The bridge functional efficiency is dependent on the traffic volume that it can withstand, which is mainly related to the existing number of lanes or the width of the deck. This parameter indicates the potential level of service and operation efficiency of a bridge. Load carrying capacity is a critical aspect of serviceability. Bridge width, overhead clearance and provision for pedestrians and cyclists are also determining issues. A poor SPF may trigger substantial remediation, bridge modifications or even bridge replacement.

4) Road/Rail Type Factor (RF): This factor is based on usage and importance of the bridge to the network addressing the road type of the bridge including street, road, freeway (FWY) or highway (HWY), bridge environment such as rural or urban, and the feature crossed such as road, waterway and railway.

5) Environmental Change Factor (ECF): This parameter considers post-design changes in climatic conditions, e.g. freeze and thaw; introduced aggressive factors such as chlorides, sulphates, carbon dioxide and other pollutants; substantial increases in traffic flow; increases of the bridge dead load due to repeated repaving; closing of joints; potential abutment rotation due to differential and/or excessive backfill material expansion; and non-anticipated alkali silica reaction [15].

Measuring the level of risk introduced by environmental change is often based on a bridge inspector's experience or laboratory tests which are conducted within the detailed inspection phase.

6) Client Impact Factor (CIF): The nature of a bridge site and the extent of the bridge remediation treatment may cause decision makers to close bridge lanes or create alternative routes or bypasses to control the traffic flow. Excessive traffic delay times often result in negative feedback from both the road users [8] and their political representatives. This factor helps build the social implications of remediation into the risk assessment process. It is a vast improvement on the 'do nothing' course of action, as this factor can be systematically weighted and considered along with the other condition rating factors. Alternatively, it can be ignored by assigning it a weight of zero during decision making.

7) Historical Factor $(H F)$ : Some bridges have historical value and some are also heritage-listed. Generally, heritage-listed bridges are rarely used by the public, but some bridges with noted historical significance may need to remain in service. 
TABLE V

RATINGS OF THE FACTORS

\begin{tabular}{|l|c|c|c|c|}
\hline & 1 & 2 & 3 & 4 \\
\hline SEF & $0<$ S.I $\leq 1$ & $1<$ S.I $\leq 2$ & $2<$ S.I $\leq 3$ & $3<$ S.I $\leq 4$ \\
\hline A.F & $\begin{array}{c}\text { Recently } \\
\text { built }\end{array}$ & New & Old & Very Old \\
\hline SP.F & Excellent & Good & Fair & Poor \\
\hline R.F & Minor & $\begin{array}{c}\text { Local } \\
\text { Access }\end{array}$ & Collectors & Arterials \\
\hline EC.F & Low & Medium & High & Very High \\
\hline CI.F & Low & Medium & High & Very High \\
\hline H.F & Low & Medium & High & Very High \\
\hline
\end{tabular}

8) Calculating the Condition Index (CI): Since the importance of the above-mentioned factors is not the same, summing up all the values is not a rational way for finding the Condition Index (CI). Therefore some weight factors should be assigned by the decision makers and maintenance experts that reflect the importance of each condition index factor.

Importance weighting should be guided by organisational policy. A weighting of zero means that a specific condition factor is judged to have no bearing on the decision making environment, whilst a rating of 4 means that the factor is extremely important. If all of the seven listed condition rating factors are assigned weights greater than zero, the relevant weighted condition index equation is as follows:

$$
\mathrm{CI}=\frac{\sum_{i}\left(w_{i} \times F_{i}\right)}{28} \quad \text { (Equation 3) }
$$

$\mathrm{W}_{i}$ is the weight of the $i$ th factor $\in[0,4]$

$\mathrm{F}_{i}$ is the assigned value of this factor $\in[1,4]$

According to the defined thresholds for the above factors, the Condition Index (CI) will be between 0 and 4 $(\mathrm{CI} \in[0,4])$.

\section{Risk Assessment (II): Dominant Constraint}

Bridge risk evaluation often serves as the basis for bridge remediation priority ranking, and is conducted periodically for the purpose of safety and functionality. The user is therefore required to assign a weighting for each constraint for individual bridges within their jurisdiction. Major risks and client constraints for bridge maintenance are categorised in Table VI.

\section{Decision Tree: Major Strategies}

Most real-world decisions are not limited to singular, unique solutions. The decisions are usually less than optimal and are drawn from a set of feasible solutions that have been termed as 'satisficing' solutions [6]. To define and categorise all the possible alternatives, a comprehensive classification should be defined. A decision tree is an appropriate decision analysis tool for this purpose. Figure II represents a decision tree which includes all the major courses of action for bridge remediation (Level 1 and 2) and some specific treatment options for concrete bridges (Level 3).

TABLE VI

MAJOR Risks AND Client CoNSTRAinTS FOR BRIDGE REMEDIATION

\begin{tabular}{|c|c|c|}
\hline Criterion & Risks & Constraints \\
\hline \multirow[b]{2}{*}{ Safety } & $\begin{array}{c}\text { Potential injury/ } \\
\text { fatality }\end{array}$ & \multirow{2}{*}{$\begin{array}{l}\text { Minimal } \\
\text { damage/ } \\
\text { Maximum } \\
\text { safety of the } \\
\text { public }\end{array}$} \\
\hline & $\begin{array}{c}\text { Damage to } \\
\text { property }\end{array}$ & \\
\hline \multirow{2}{*}{ Functionality } & $\begin{array}{l}\text { Low level of } \\
\text { service }\end{array}$ & $\begin{array}{c}\text { Maximum } \\
\text { service life/ } \\
\text { Load bearing } \\
\text { capacity }\end{array}$ \\
\hline & $\begin{array}{c}\text { Closure of a } \\
\text { strategic/ regional } \\
\text { route }\end{array}$ & $\begin{array}{c}\text { Minimal traffic } \\
\text { disruption }\end{array}$ \\
\hline \multirow{2}{*}{ Sustainability } & $\begin{array}{l}\text { Excessive } \\
\text { remediation cost }\end{array}$ & Minimal cost \\
\hline & $\begin{array}{l}\text { Excessive work } \\
\text { implication }\end{array}$ & $\begin{array}{l}\text { Minimal work } \\
\text { implication }\end{array}$ \\
\hline \multirow{2}{*}{ Environment } & $\begin{array}{c}\text { Environmental } \\
\text { damage }\end{array}$ & $\begin{array}{c}\text { Minimal } \\
\text { environmental } \\
\text { damage }\end{array}$ \\
\hline & $\begin{array}{l}\text { Not aesthetically } \\
\text { pleasing }\end{array}$ & $\begin{array}{l}\text { Maximum } \\
\text { aestheticism }\end{array}$ \\
\hline \multirow{2}{*}{ Legal/ Political } & $\begin{array}{l}\text { Major changes in } \\
\text { standards }\end{array}$ & \multirow{2}{*}{$\begin{array}{c}\text { Minimum } \\
\text { vulnerability to } \\
\text { political } \\
\text { pressures }\end{array}$} \\
\hline & $\begin{array}{l}\text { Major changes in } \\
\text { governance } \\
\text { strategies }\end{array}$ & \\
\hline
\end{tabular}

For each of those treatment options in Level 3, there are a few sub branches which have not been addressed at this level.

Preventive and routine maintenance can be conducted as a supportive action for all the minor and major rehabilitation alternatives.

"Do nothing" is a very common course of action. In many instances, enough funds are not available and the bridge managers have to allocate the budget for the structures of higher priority.

\section{E. Decision Analysis Tool}

The ranking method in this research is based on Multi Attribute Utility Theory (MAUT). The Analytical Hierarchy Process (AHP) method [22] has also been primarily examined. After the comparison, the advantages and limitations of the two methods were analysed to select the most appropriate method for decision making. 


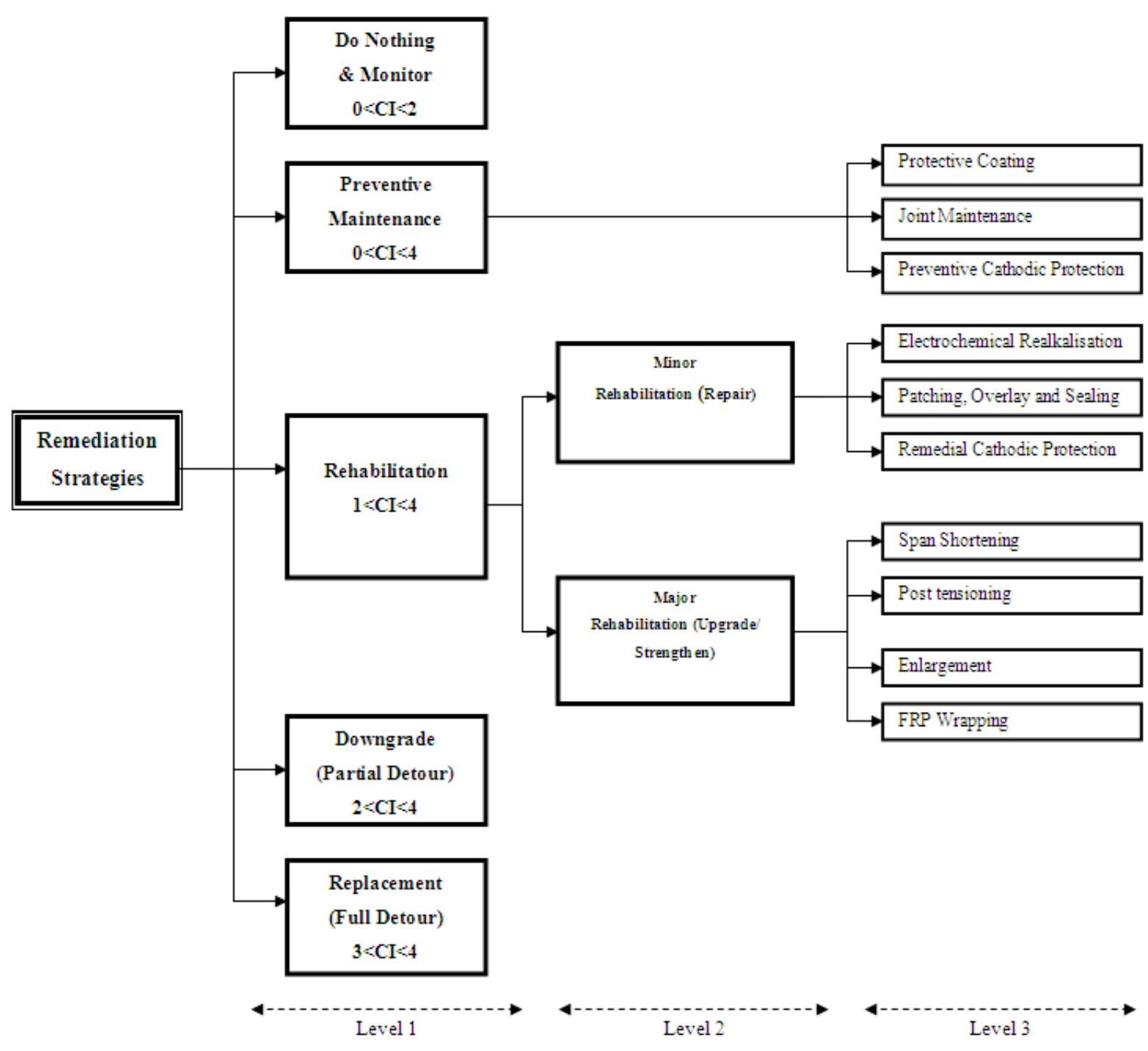

FIGURE II

Decision Tree for Possible Bridge Remediation Courses of Action

The advantages of the AHP method are that it supplies a systematic approach through a hierarchy and it has an objectivity and consistency. On the other hand, the limitations are that calculation of a pair-wise comparison matrix for each criterion is quite complex and as the number of constraints and/or alternatives increases, the number of calculations for a pair-wise comparison matrix rises considerably. Moreover if a new alternative is added, all the calculation processes have to be restarted again.

The advantages of the MAUT approach are that the implicated judgments are made explicitly, the value information can be used in many ways to help simplify a decision process, and a decision maker typically learns a great deal through these joint efforts to construct their views on their priorities.

However the determination of the maximum and minimum ranges of the attributes and deriving work from the utility functions are perceived limitations [23]. After the analysis of the two methods it has been concluded from industry case studies that the MAUT is more practical for this applied research. Through the MAUT process, firstly, the problem under consideration is broken down into a hierarchy (Figure III).

Decision criteria are collected during interviews with bridge engineers and asset managers. All the elements (goal, objectives and constraints) are organized into a fourlevel hierarchy structure, which consider all the main aspects of the problem. This approach deals with identifying the overall goal and proceeding downward until the measure of value is included. The first level of the structure is the overall goal of the ranking. The second level contains the objectives (criteria) defined to achieve the main goal. The third level holds the constraints (sub criteria) to be employed for assessing the objectives. The last level is added for the remediation treatment alternatives. Each criterion has a weight indicating its importance which is defined by the decision maker [17]. 


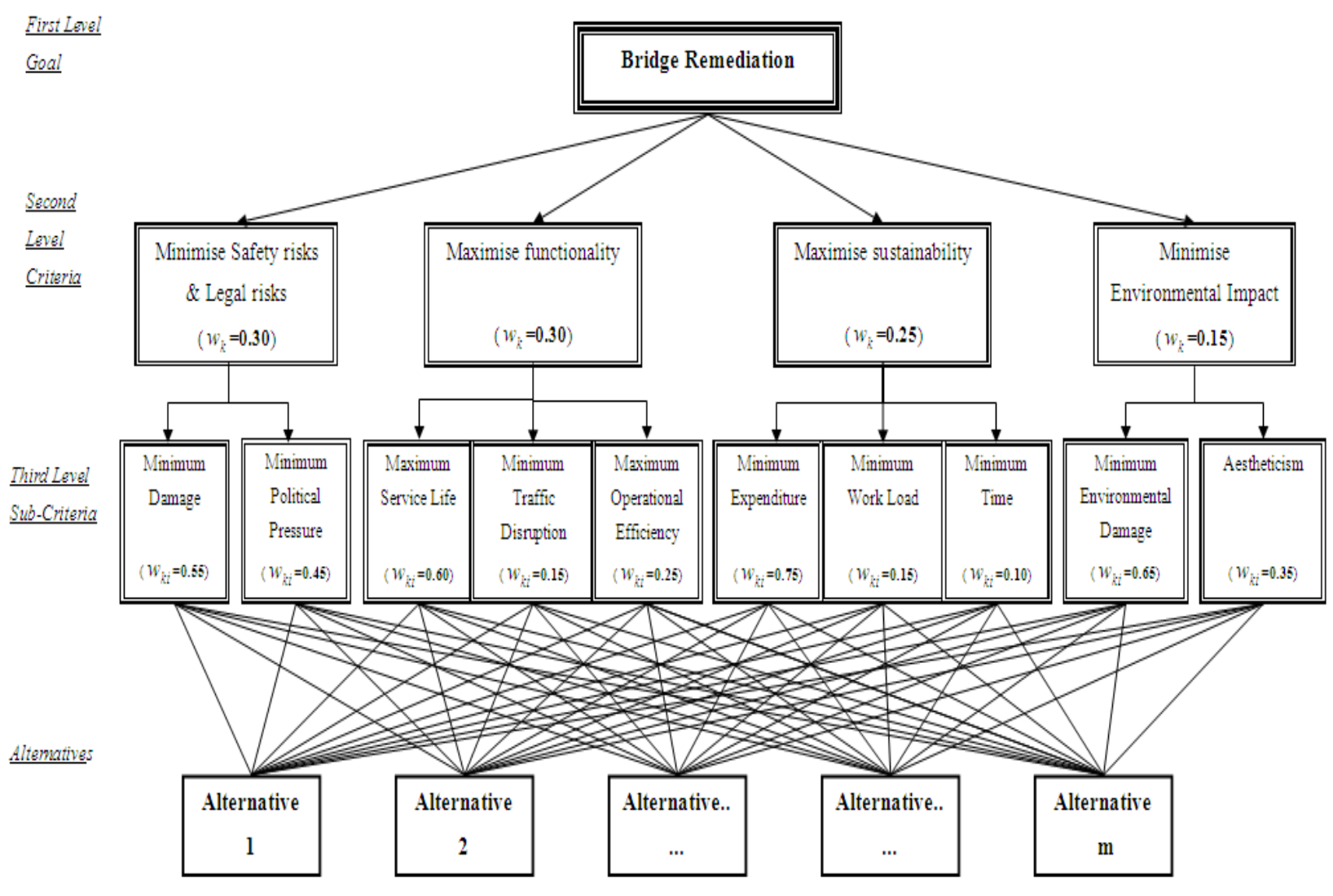

FIGURE III

A Typical Hierarchy Structure for Bridge Remediation

In the majority of cases based on the MAUT, the weights associated with the criteria can clearly reflect the relative importance of the criteria if the scores $\mathrm{a}_{\mathrm{ij}}$ are from a dimensionless scale. The basic step of MAUT is the application of utility functions to transform the raw performance values of the alternatives against the constraints, both objective and subjective to a common dimensionless scale so that a more favoured option gains a higher utility value [24].

Weights of the criteria and sub criteria are usually defined based on the expert's judgments (which should reflect organisational policy) extracted during the problem solving. Final weights are obtained through normalising the sum of the scores to one [17].

Simple Multi Attribute Rating Technique (SMART) is a form of MAUT. In order to simplify the process, the utility function can be replaced by some scores which indicate the relative importance level of each treatment alternative with respect to the decision criteria.

The overall ranking value of each alternative $x_{j}$ is expressed as follows:

$$
x_{j}=\sum_{i=1}^{m} w_{k} w_{k i} a_{i j} \quad j=1, \ldots, m
$$

(Equation 4)

$W_{\mathrm{k}}$ and $W k i$ are the weights of criteria and sub criteria $\mathrm{a}_{\mathrm{ij}}$ is the importance level of $j$ th alternative in respect to the $i$ th sub criterion and $k$ th criterion.

The chosen alternative is normally the option with the highest overall score.

\section{MODEL TESTING}

Verification is concerned with establishing the internal correctness of a model. It is conducted by the model builder/expert to detect and eliminate any errors made in early prototypes and to confirm critical variable ranges for which the model can be applied [25].

In order to verify the application of the proposed model, a few concrete bridges located in N.S.W have been chosen. These bridges have a high asset value and limited financial resources are available to maintain these bridges at a high working standard. It is therefore important to put considerable effort into the risk assessment process to ensure that the structures are analysed carefully and any defects are rectified early, before they become a significant issue.

Required data was extracted from reports provided by the bridge management division of the Roads and Traffic Authority (RTA). The Condition Index of all those bridges has been calculated in order to prioritise them for any probable maintenance/repair strategies and possible budget 
allocation. Firstly the Structural Index (S.I) of the bridges was estimated based on the bridge inspection reports. Then the overall condition has been evaluated for all those bridges considering the parameters being addressed in part B. TABLE VII and TABLE VIII represent the condition assessment procedure of a 39 year old bridge situated approximately 10 kilometers south of Wollongong, adjacent to the coastline (introduced as Bridge $\mathrm{X}$ in this paper). According to the inspection reports all the piers are footed in saline water, and there is ongoing cracking of columns and headstocks. Testing revealed very high chloride contamination levels. These levels implied that corrosion was past the acceptable threshold, and remediation was required that could slow the degradation process. Some concerns have been also reported regarding to load bearing capacity and serviceability of the bridge.

Table VII includes the condition of all the elements in terms of their structural efficiency, considering their material vulnerability and structural importance and finally the overall Structural Index (S.I) has been calculated according to Equation 1 and Equation 2. Table VIII shows the summary of condition factors and their associated weights (based on expert judgments) for the bridge and finally the overall condition index is estimated based on Equation 3.

TABLE VII

Structural Condition Assessment for Bridge X

\begin{tabular}{|c|c|c|c|c|c|c|c|c|c|c|c|}
\hline \multirow{2}{*}{$\begin{array}{l}\text { Element } \\
\text { Code }\end{array}$} & \multirow{2}{*}{$\begin{array}{c}\text { Element } \\
\text { Description }\end{array}$} & \multirow{2}{*}{\begin{tabular}{|c|} 
Total \\
Quantit \\
$\mathrm{y}$ \\
\end{tabular}} & \multirow[t]{2}{*}{ Units } & \multicolumn{4}{|c|}{$\begin{array}{l}\text { Estimated Quantity in } \\
\text { condition state }\end{array}$} & \multirow{2}{*}{$\begin{array}{l}\text { ESCI } \\
\left(E_{q 1}\right)\end{array}$} & \multirow[t]{2}{*}{$\mathrm{Si}$} & \multirow[t]{2}{*}{$\mathrm{mi}$} & \multirow[t]{2}{*}{$\mathrm{CI}$} \\
\hline & & & & 1 & 2 & 3 & 4 & & & & \\
\hline BELA & Elastomeric Bearing Pad & 66 & ea & 66 & 0 & 0 & 0 & 1.00 & 3 & 3 & 9.00 \\
\hline CABW & Concrete-Abutment and Wingwalls & 54 & $\mathrm{~m} 2$ & 54 & 0 & 0 & 0 & 1.00 & 2 & 2 & 4.00 \\
\hline CDSL & Concrete-Deck Slab & 6254 & $\mathrm{~m} 2$ & 6239 & 0 & 15 & 0 & 1.00 & 3 & 2 & 6.03 \\
\hline CPHS & Concrete-Pier Headstock & 1893 & $\mathrm{~m} 2$ & 1885 & 0 & 8 & 0 & 1.01 & 4 & 2 & 8.07 \\
\hline CPIL & Concrete-Piles/Piers & 695 & $\mathrm{~m} 2$ & 590 & 3 & 0 & 102 & 1.44 & 4 & 2 & 11.56 \\
\hline CPRG & Concrete-Pre-tensioned Girder & 5901 & $\mathrm{~m} 2$ & 5739 & 162 & 0 & 0 & 1.03 & 4 & 4 & 16.44 \\
\hline JNOS & Joint - No Seal & 32 & $\mathrm{~m}$ & 31 & 1 & 0 & 0 & 1.03 & 1 & 3 & 3.09 \\
\hline JPOS & Pourable / Cork Joint Seal & 528 & $\mathrm{~m}$ & 0 & 0 & 528 & 0 & 3.00 & 1 & 3 & 9.00 \\
\hline MAPP & Approach Carriageway & 4 & ea & 3 & 1 & 0 & 0 & 1.25 & 1 & 3 & 3.75 \\
\hline MBAT & Batter protection & 127 & $\mathrm{~m} 2$ & 127 & 0 & 0 & 0 & 1.00 & 1 & 3 & 3.00 \\
\hline $\mathrm{MGCL}$ & General Cleaning & 33 & ea & 0 & 0 & 33 & 0 & 3.00 & 1 & 3 & 9.00 \\
\hline MWES & Wearing surface & 4811 & $\mathrm{~m} 2$ & 3811 & 1000 & 0 & 0 & 1.21 & 1 & 3 & 3.62 \\
\hline MWWY & Waterway & 1 & ea & 0 & 1 & 0 & 0 & 2.00 & 1 & 3 & 6.00 \\
\hline RMET & Metal Railing & 1203 & $\mathrm{~m}$ & 1183 & 0 & 20 & 0 & 1.03 & 1 & 1 & 1.03 \\
\hline RMIS & Miscellaneous Railing & 600 & $\mathrm{~m}$ & 580 & 0 & 20 & 0 & 1.07 & 1 & 1 & 1.07 \\
\hline RPNT & Railing Paint Work & 1203 & $\mathrm{~m}$ & 0 & 0 & 1203 & 0 & 3.00 & 1 & 3 & 9.00 \\
\hline UCPL & Underwater CPIL - Concrete-Pile & 769 & $\mathrm{~m} 2$ & 769 & 0 & 0 & 0 & 1.00 & 4 & 2 & 8.00 \\
\hline & S.I & & & & & & & & & & 0.41 \\
\hline
\end{tabular}

Bridge $X$ had the highest overall CI (1.21) in comparison to the rest of bridges $(0.76,1.01,0.86$ and 0.43 ). Therefore it has been considered as a top priority for action.

Excluding the "Do nothing", "Replacement" and "Downgrading" options, "routine/preventive maintenance" and "minor rehabilitation/repair" for different elements were the most rational remediation strategies. For each of the observed defects some treatment options are usually proposed by the inspectors/bridge experts. For example there were three alternatives for repairing the piers; recasting with concrete, surface coating and cathodic protection. According to the SMART based decision support framework presented in TABLE IX, cathodic protection $(\mathrm{CP})$ had the highest score in the proposed system. The bridge was considered to be large enough to warrant an Impressed Current Cathodic Protection (ICCP). The decision made by the RTA was also the same. It is a good example to demonstrate the validity of the model.

TABLE VIII

Overal CONDITION INDEX FOR BRIDGE X

\begin{tabular}{cccccccc} 
& SE.F & A.F & SP.F & R.F & EC.F & CI.F & H.F \\
\hline$F i$ & 1 & 2 & 2 & 3 & 4 & 1 & 1 \\
$w i$ & 4 & 2 & 3 & 2 & 3 & 2 & 0 \\
$\left(w i^{*} F i j\right.$ & 4 & 4 & 6 & 6 & 12 & 2 & 0 \\
& \multicolumn{5}{c}{$C I=\sum(w i * F i) / 28=1.21$}
\end{tabular}


TABLE IX

Ranking the Possible Treament Strategies for Piers of Bridge X Using Smart

\begin{tabular}{|c|c|c|c|c|c|c|c|c|c|c|}
\hline \multirow[t]{2}{*}{ Criteria } & \multirow[t]{2}{*}{$\mathrm{Wk}_{\mathrm{k}}$} & \multirow[t]{2}{*}{ Sub-Criteria } & \multirow[t]{2}{*}{ Wki } & \multirow[t]{2}{*}{ Wk*Wki } & \multicolumn{2}{|c|}{ Surface Coating } & \multicolumn{2}{|c|}{$\begin{array}{l}\text { Recasting with } \\
\text { Concrete }\end{array}$} & \multicolumn{2}{|c|}{$\begin{array}{l}\text { Cathodic } \\
\text { Protection }\end{array}$} \\
\hline & & & & & $a_{i j}$ & $\mathrm{xj}$ & $a_{i j}$ & $\mathrm{xj}$ & $a_{i j}$ & $\mathrm{x}_{\mathbf{j}}$ \\
\hline \multirow{2}{*}{$\begin{array}{c}\text { Minimise Safety Risks } \\
\& \\
\text { Legal Risks }\end{array}$} & \multirow{2}{*}{0.30} & Minimum Damage & 0.55 & 0.17 & 1 & 0.17 & 2 & 0.33 & 4 & 0.66 \\
\hline & & $\begin{array}{c}\text { Minimum Legal/ Political } \\
\text { Pressure }\end{array}$ & 0.45 & 0.14 & 3 & 0.41 & 3 & 0.41 & 3 & 0.41 \\
\hline \multirow{3}{*}{ Maximise Functionality } & \multirow{3}{*}{0.30} & Maximum Service Life & 0.60 & 0.18 & 2 & 0.36 & 3 & 0.54 & 5 & 0.90 \\
\hline & & Minimum Traffic Disruption & 0.15 & 0.05 & 4 & 0.18 & 4 & 0.18 & 4 & 0.18 \\
\hline & & Maximum Operational Efficiency & 0.25 & 0.08 & 2 & 0.15 & 3 & 0.23 & 4 & 0.30 \\
\hline \multirow{3}{*}{ Maximise Sustainability } & \multirow{3}{*}{0.25} & Minimum Expenditure & 0.75 & 0.19 & 4 & 0.75 & 3 & 0.56 & 1 & 0.19 \\
\hline & & Minimum Work Load & 0.15 & 0.04 & 4 & 0.15 & 3 & 0.11 & 2 & 0.08 \\
\hline & & Minimum Time & 0.10 & 0.03 & 4 & 0.10 & 3 & 0.08 & 2 & 0.05 \\
\hline \multirow[t]{2}{*}{$\begin{array}{c}\text { Minimise } \\
\text { Environmental Impact }\end{array}$} & \multirow{2}{*}{0.15} & $\begin{array}{c}\text { Minimum Environmental } \\
\text { Damage } \\
\end{array}$ & 0.65 & 0.10 & 2 & 0.20 & 3 & 0.29 & 3 & 0.29 \\
\hline & & Maximum Aestheticism & 0.35 & 0.05 & 3 & 0.16 & 2 & 0.11 & 1 & 0.05 \\
\hline TOTAL & & & & & & 2.61 & & 2.83 & & 3.10 \\
\hline
\end{tabular}

\section{CONCLUSION}

A Decision Support model for remediation planning of bridges has been achieved through an extensive literature review and expert judgment derived during case studies with bridge engineers and asset managers. The framework includes the Condition Index (CI) evaluation of the bridge as the primary sieve for selecting the major courses of action such as 'Do nothing \& monitor', 'Preventive maintenance', 'Rehabilitation' (minor or major) and 'Downgrading'. This index addresses various factors which have different weights in terms of their influence on the condition of the bridge. Generally, the most important parameters are related to structural and functional performance. CI can also be used to rank and prioritise bridge projects in a way that the decision maker can identify bridges with the highest concern for intervention. For each of the prioritised projects, the decision maker (bridge engineer/ asset manager) is required to choose a remediation strategy to improve the bridge condition or at least keep the condition in a steady state. Possible remediation alternatives are ranked through Simple Multi Attribute Rating Techniques (SMART) which is a subcategory of Multi Attribute Utility Technique (MAUT) which the decision criteria should be drawn from the secondary risk analysis process. Simplicity and flexibility are the main attributes of this modelling approach which distinguishes it from other decision analysis tools such as AHP. In this research, model verification is accomplished through semi-structured interviews and case studies.
Interviews with twenty two potential system users have been conducted to determine information requirements, decision points, dominant constraints and other relevant information considering the limitation of subjectivity and inability of users to verbalise their practice. Classifications and information presented in TABLE III-IX and FIGURE I-III have been supported by the data collected through semi-structured interview with the potential decision makers.

A real case study is used to validate the proposed decision support model. The analysis of the case study shows that the developed model quantifies the overall condition properly and evaluates the possible alternatives and finally suggests valid decisions regarding selecting a solution for bridge improvement. Successful validation enables the decision makers to rely on the proposed model. It can also support the applicability of the model for other civil infrastructures.

\section{ACKNOWLEDGEMENT}

The writers wish to thank Mr Kevin.Kennedy from the Roads and Traffic Authority (RTA), Mr. Tim Conford from Wollongong City Council (WCC), Dr. Ben Chung from Railcorp NSW, Dr.Ahmad Shayan (ARRB), and Dr. Mohammad Ali (GHD) for their continuous support particularly in data collection and model verification. 


\section{REFERENCES}

[1] D.J.D. Vanier, "Why Industry Needs Asset Management Tools", Journal of Computing in Civil Engineering, vol. 15, no. 1, pp. 35-43, 2001.

[2] B. Lemass, W. Young, "An Intelligent Decision Support System for Road Pavement Design", Journal of the Eastern Asia Society for Transportation Studies, Tokyo, Japan, vol. 2, no. 2, pp. 505-524, 1997.

[3] I.M. Shohet, E. Perelstein, "Decision Support Model for the Allocation of Resources in Rehabilitation Projects", Journal of Construction Engineering and Management, vol. 130, no. 2, pp. 249-257, 2004

[4] L.J. Krajewski, L.P. Ritzman, M.K. Malhorta, "Operations Management Processes and Value Chains", Pearson Prentice Hall, Upper Saddle River, N.J., 2007.

[5] A.K. McCowan, S. Mohamed, "Decision Support System to Evaluate and Compare Concession Options", Journal of Construction Engineering and Management, vol. 133, no. 2, pp. 114-123, 2007.

[6] B. Lemass, D.G. Carmichael, "Front End Project Management", Pearson Prentice Hall, Sydney, Australia, 2008.

[7] Austroads, "An Overview of the Australian and New Zealand Systems", Sydney, Australia, 2000.

[8] ARRB Transport Research Ltd., "Local Roads Bridge Manual", 2000.

[9] M.G. Stewart, "Reliability-Based Assessment of Ageing Bridges Using Risk Ranking and Life Cycle Cost Decision Analyses", Reliability Engineering \& System Safety, vol. 74, no. 3, pp. 263-273, 2001.

[10] S. Rostam, "Service life design - the European approach" Concrete International, vol. 15, no. 7, pp. 24-32, 1993

[11] M. Rashidi, B. Lemass, P. Gibson, "A decision support system for concrete bridge maintenance", Proceedings of ISCM II \& EPMESC XII, pp. 1372-1377, 2010.

[12] B. Lemass, "Structured Conceptual Design: The New Frontier", Pearson Prentice Hall, Sydney, Australia, 2004

[13] S.B. Eom, S.M. Lee, E.B. Kim, C. Somarajan, "A survey of decision support system applications", The Journal of the Operational Research Society, vol. 49, no. 2, pp. 109-120, 1998.

[14] R.B. Faiz, E.A. Edirisinghe, "Decision Making for Predictive Maintenance in Asset Information Management", Journal of Information, Knowledge, and Management, vol. 4, 2009.

[15] F.A. Branco, J. Brito, "Handbook of Concrete Bridge Management", ASCE Press, 2004.

[16] Road \& Traffic Authority of New South Wales, RTA Bridge Inspection Procedure, RTA, Sydney, NSW, 2007.

[17] S.A. Dabous, S. Alkass, "A multi-attribute ranking method for bridge management", Journal of Engineering, Construction and Architectural Management, vol. 17, no. 3, pp. 282-291, 2010.

[18] M. Rashidi, B. Lemass, "Holistic decision support for bridge remediation", The $4^{\text {th }}$ International Conference on Construction Engineering and Project Management, ICCEPM, S2-4 , 2011.

[19] S. Sasmal, K. Ramanjaneyulu "Condition evaluation of existing reinforced concrete bridges using fuzzy based analytic hierarchy approach", Expert Systems with Applications, vol. 35, no. 3, pp. 1430-1443, 2008.

[20] A.B. Tee, M.D. Browman, K.C. Sinha "A fuzzy mathematical approach for bridge condition evaluation", Journal: Civil engineering systems, vol. 5, no. 1, pp. 17-24, 1988 .

[21] H.G Melhem, S. Aturaliya, "Bridge Condition Rating Using an Eigenvector of Priority Settings", Computer-Aided Civil and Infrastructure Engineering, vol. 11, no. 6, pp. 421-432, 1996.

[22] T.S. Saaty, "Decisions for Leaders: The Analytic Hierarchy Process", University of Pittsburgh, Pennsylvania, 1990.

[23] S.K. Kim, O. Song, "A MAUT approach for selecting a dismantling scenario for thermal column in KRR-1", Annals of Nuclear Energy vol. 36, no. 2, pp. 145-150, March 2009.

[24] J. Fülöp, "Introduction to Decision Making Methods", Laboratory of Operations Research and Decision Systems: Computer and Automation Institute, Hungarian Academy of sciences, 2005.

[25] R.M. O'Keefe, O. Balci, E.P. Smith, "Validating Expert System Performance", in Validating and Verifying Knowledge-Based
Systems, Eds. U. Guptu, IEEE Computer Society Press, Los Alamitos, CA, 1991. 